\title{
Simulation Research on Photovoltaic Power System Electromagnetic Transient Model
}

\author{
Tao Shi ${ }^{1,2, *}$, Shan $\mathrm{Gao}^{1}$ and Linan $\mathrm{Qu}^{2}$ \\ ${ }^{I}$ Department of Electrical Engineering, Southeast University, Nanjing, China, 210096 \\ ${ }^{2}$ Department of Renewable Energy, China Electric Power Research Institute, Nanjing, China, 210003
}

\begin{abstract}
With an increasing number of photovoltaic (PV) power stations integrated into the power grid, a model which is suitable to be used in the power system electromagnetic transient simulation is required. So in this paper, a detailed PV power system model is provided. In the model, the core components, such as PV array and inverter are all considered. Then in a certain case, which contains a PV power system, are simulated and analyzed. The results show that the model could reflect the electromagnetic characteristics of PV power system effectively.
\end{abstract}

Keywords: Electromagnetic transient, inverter, modeling and simulation, PV array, PV power system.

\section{INTRODUCTION}

As a type of renewable energy generation technology, PV power systems are popular in many countries and an increasing number of PV stations are being integrated into the power grid. Different from other traditional rotating generation units, PV systems are a static generation unit, which are based on the power electronics and photoelectric conversion technologies without inertia. The output of PV system fluctuates with the variation of irradiance, temperature and other environmental conditions. These effects would bring negative effects on the security and stability of the whole power system [1-3]. Therefore a suitable and effective simulation model is required in the power system analysis and assessment, when a PV station integrates into the power grid. Through the modeling and simulation, the effects on grid brought by PV station and the corresponding measures will be obtained and provided. Finally, the PV station integrates into the grid adequatly.

According to the different simulation purposes, the power system simulation models are mainly classified and used in the scenarios of power flow calculation, short-circuit current calculation, electromagnetic transient simulation and electromechanical transient simulation. And due to the structure and scale of PV power system, the modeling process consists of parts modeling (such as (PV array, inverter, etc), unit modeling and station modeling. Many institutes and organizations such as: International Electrotechnical Commission (IEC), Western Electricity Coordinating Council (WECC), Electric Power Research Institute (EPRI), DIgSILENT GmbH, GE etc, have engaged in the research about it [4-6]. IEC, WECC, EPRI have focused more attention on the general modeling and model verification and the equipment companies focus on the special development model for their own products [7-9].

In this paper, the electromagnetic model of PV power system is provided and analyzed. The key parts of PV system are considered such as PV array and a inverter. And then a certain case is simulated and analyzed, in order to demonstrate the effectivness and validity of this model.

\section{THE TYPICAL STRCUTURE OF PV POWER SYS- TEM}

A typical PV station consists of PV array, inverter unit, step-up transformer, in-station lines, reactive compensation devices and station main step-up transformer, as shown in the Fig. (1). The PV array produces DC electricity by photovoltaic effect, the inverter convert the DC current to AC current and steps up the voltage, transmits into the grid by transformers and lines.

Accordingly, the PV station models mainly consist of PV unit models, electricity collector and voltage set-up system models and reactive compensation models etc [10-12]. Because that the models of lines, transformer and reactive compensation devices have been studied mature in many literatures, these models are not repeated in this paper.

\section{THE MODEL OF PV ARRAY}

The PV array consists of many series and parallel PV modules. A theoretical model schematic is shown in the Fig. (2).

Based on which, the non-linear IV characteristics equations are established and provided [7]: 


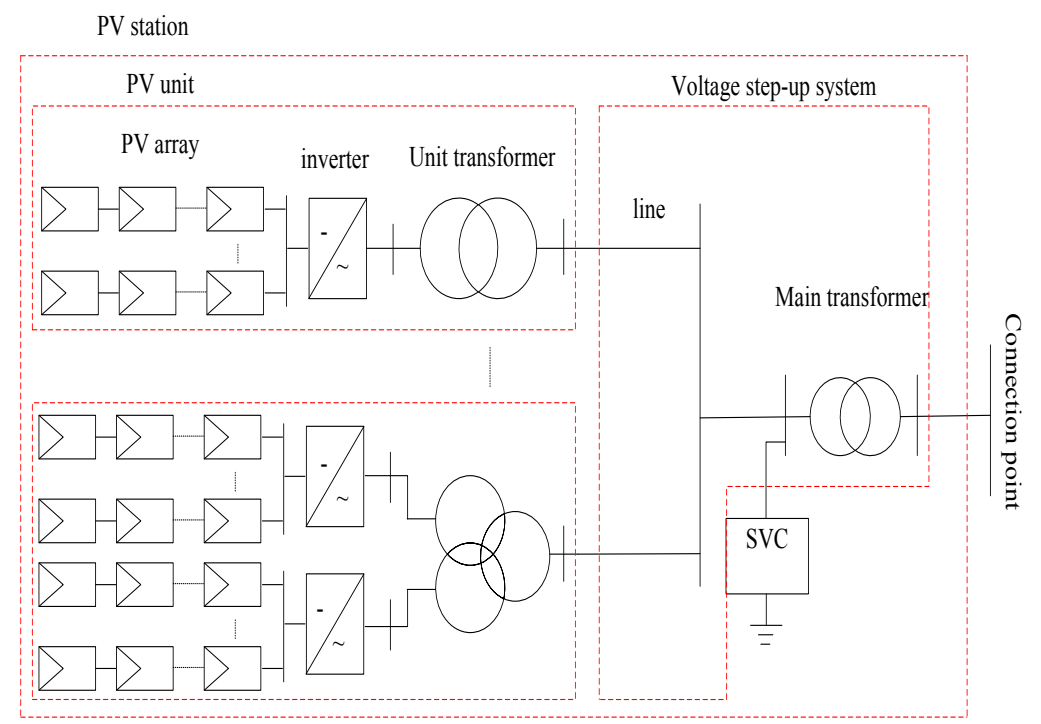

Fig. (1). Typical Structure of PV Station.

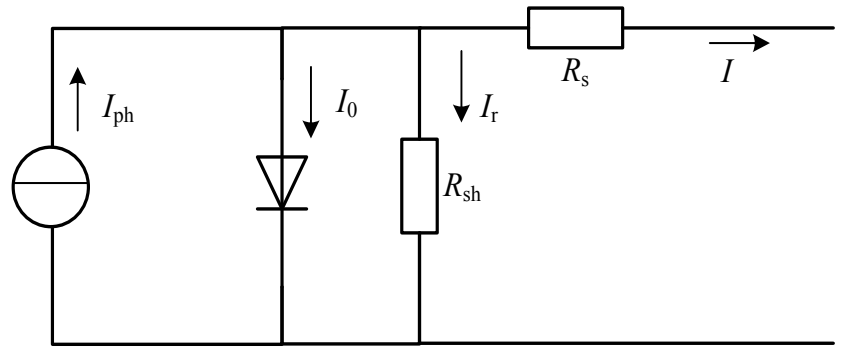

Fig. (2). Theoretical schematic of PV module.

$$
I=I_{p h}-I_{0}\left\{\exp \left[\frac{q\left(U+I R_{s}\right)}{A k T}\right]-1\right\}-\frac{\left(U+I R_{s}\right)}{R_{s h}}
$$

Where:

$\mathrm{I}_{\mathrm{ph}}$ : photo-generated current, vary along with the change of irradiance and temperature.

$\mathrm{I}_{0}$ : reverse saturation current of bypass-diode, influenced by temperature.

$\mathrm{q}:$ electron charge, $1.602 \mathrm{e}^{-19} \mathrm{C}$.

$\mathrm{k}$ : Boltzmann constant, $1.381 \mathrm{e}-23 \mathrm{~J} / \mathrm{K}$.

A: diode curve factor, valued between 1 and 2.

$\mathrm{R}_{\mathrm{s}}$ : the equivalent series resistance.

$\mathrm{R}_{\mathrm{sh}}$ : the equivalent parallel resistance.

$\mathrm{T}$ : thermodynamic temperature.

With the condition of high irradiance, $\mathrm{I}_{\mathrm{ph}}>>\left(\mathrm{U}+\mathrm{IR}_{\mathrm{s}}\right) / \mathrm{R}_{\mathrm{sh}}$, , the dark current is very small. Therefore, the short circuit current of PV module is $\mathrm{I}_{\mathrm{sc}} \approx \mathrm{I}_{\mathrm{ph}}$. Generally, the series resistance $R_{s}$ is very small and the bypass resistance $R_{s h}$ is very large. This makes the energy conversion efficiency very sensitive to the change of $R_{s}$, but scarcely influenced by Rsh. For the ideal single PV modules, there is no series resistance and bypass resistance, i.e. $\mathrm{R}_{\mathrm{s}}=0, \mathrm{R}_{\mathrm{sh}}=\infty$.
The formula can be simplified as [8-9]:

$$
\begin{aligned}
& I=I_{\mathrm{SC}} \cdot\left[1-\alpha\left(e^{\beta U}-1\right)\right] \\
& \alpha=\left(\frac{I_{\mathrm{SC}}-I_{\mathrm{m}}}{I_{\mathrm{SC}}}\right)^{\frac{U_{\mathrm{OC}}}{U_{\mathrm{OC}}-U_{\mathrm{m}}}} \\
& \beta=\frac{1}{U_{\mathrm{OC}}} \cdot \ln \left(\frac{1+\alpha}{\alpha}\right)
\end{aligned}
$$

It is shown that the mathematic model of PV module can be described with these four technical parameters (open circuit voltage $U_{o c}$, short circuit current Isc, voltage at the max power point $\mathrm{Um}$, current at the max power point $\mathrm{I}_{\mathrm{m}}$ ). These parameters are all obtained in the standard test conditions (reference irradiance $\mathrm{S}_{\text {ref }}=1000 \mathrm{~W} / \mathrm{m}^{2}$ and reference ambient temperature $\mathrm{T}_{\text {ref }}=25^{\circ} \mathrm{C}$ ).

If the PV module is operating at a random point, the IV characteristics can be derived from the formula (2):

$$
\begin{aligned}
& \Delta T=T-T_{\text {ref }} \\
& \Delta S=S-S_{\text {ref }} \\
& I_{\mathrm{SC}(\mathrm{m})}^{\prime}=I_{\mathrm{SC}(\mathrm{m})} \cdot \frac{S}{S_{\text {ref }}} \cdot(1+a \Delta T) \\
& U_{\mathrm{OC}(\mathrm{m})}^{\prime}=U_{\mathrm{OC}(\mathrm{m})} \cdot(1-c \Delta T) \cdot \ln (e+b \Delta S)
\end{aligned}
$$




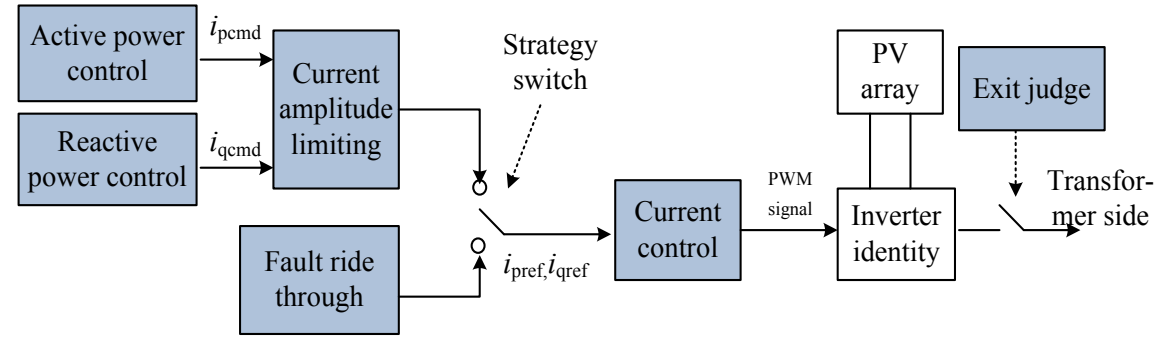

Fig. (3). Schematic of PV electromagnetic transient models.

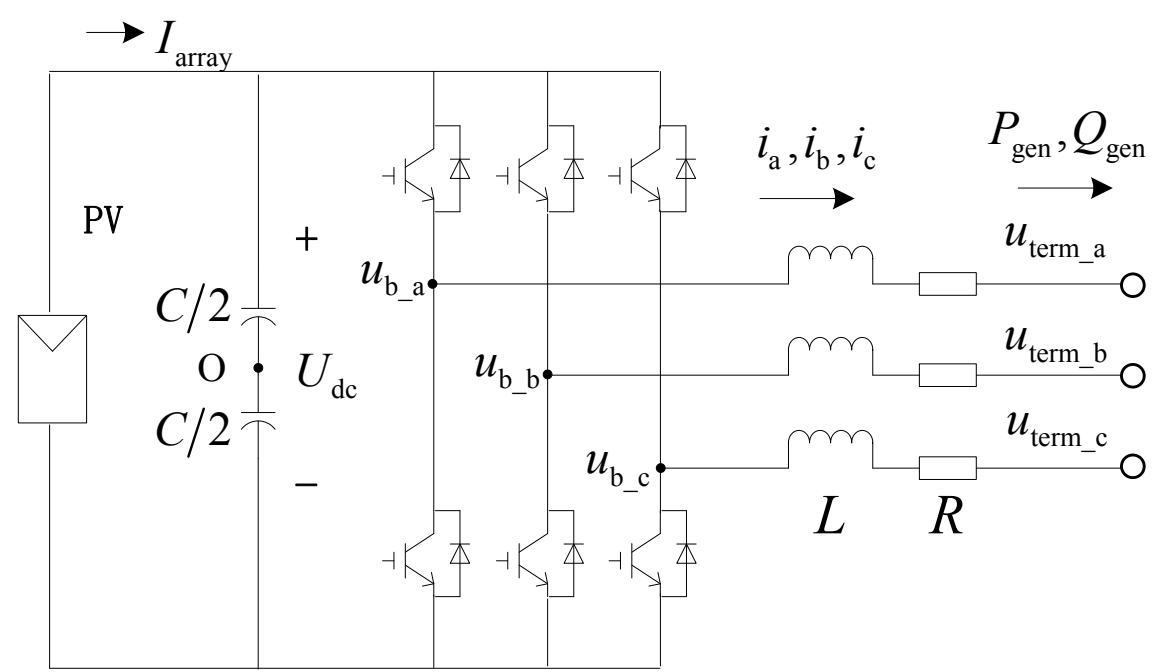

Fig.(4). Circuit topology of inverter.

In which, for the silicon PV modules, the typical recommended value of $\mathrm{a}, \mathrm{b}$ and $\mathrm{c}$ are $0.0025,0.0005$ and 0.00288 respectively.

\section{THE MODEL OF PV INVERTER}

The electromagnetic transient models of PV are divided into two parts: controller models and identity models, as shown in Fig. (3). The controller models mainly include active power control strategy, reactive strategy, current amplitude limiting strategy, fault ride through strategy, etc [13-15]. The control systems are usually built in D-Q rotating coordinate system, in order to realize the decoupling of active and reactive power control. The identity models mainly refer to the circuit model of inverter.

\subsection{Identity of Inverter}

The circuit topology of inverter is of three-phase bridge circuit, each phase of circuit is divided into upper and lower bridge arms. Each bridge arm is composed of IGBT and the opposite parallel diode. Because of the continued flow of reversed diode, IGBT and diode consists of a two-way switch, so that the two-way flow of current and energy is possible, It is shown as Fig. (4).

According to Kirchhoff's voltage law, the AC differential equations of inverter can be obtained in the static coordinate [16-18].
$L \frac{d}{d t}\left[\begin{array}{c}i_{\mathrm{a}} \\ i_{\mathrm{b}} \\ i_{\mathrm{c}}\end{array}\right]=\left[\begin{array}{c}u_{\mathrm{b} \_\mathrm{a}} \\ u_{\mathrm{b} \_\mathrm{b}} \\ u_{\mathrm{b} \_\mathrm{c}}\end{array}\right]-\left[\begin{array}{c}u_{\text {term_a }} \\ u_{\text {term_b }} \\ u_{\text {term } \_\mathrm{c}}\end{array}\right]-R\left[\begin{array}{c}i_{\mathrm{a}} \\ i_{\mathrm{b}} \\ i_{\mathrm{c}}\end{array}\right]=\left[\begin{array}{c}s_{\mathrm{a}} \\ s_{\mathrm{b}} \\ s_{\mathrm{c}}\end{array}\right] U_{\mathrm{dc}}-\left[\begin{array}{c}u_{\mathrm{term} \_\mathrm{a}} \\ u_{\text {term_b }} \\ u_{\text {term } \_\mathrm{c}}\end{array}\right]-R\left[\begin{array}{c}i_{\mathrm{a}} \\ i_{\mathrm{b}} \\ i_{\mathrm{c}}\end{array}\right]$

Where, $S_{a}, S_{b}$ and $S_{c}$ are the switch functions representing the state of switch on the upper or lower three-phase bridge arm.

\subsection{Active Power Control Strategy}

The active power control strategy mainly includes MPPT control and DC voltage control. Under the normal condition, the MPPT controller put out the reference voltage Udcref, and the deviation between $\mathrm{U}_{\mathrm{dcref}}$ and $\mathrm{Udc}$ is put into the PI controller, then the reference value of active current ipcmd is provided (Fig. 5).

\subsection{Reactive Power Control Strategy}

There are two control modes for reactive control: power factor mode and reactive power mode. In the power factor mode, the reactive power order $\mathrm{Q}_{\mathrm{cmd}}$ is calculated according to power factor $\mathrm{PF}_{\text {ref }}$ and active power Pgen. In the reactive power mode, the referenced value $\mathrm{Q}_{\mathrm{ref}}$ is set as a constant or obtained from the station control system. The deviation between $\mathrm{Q}_{\mathrm{cmd}}$ and $\mathrm{Q}_{\mathrm{gen}}$ is put into the PI controller and then the referenced reactive current iqcmd is obtained. In the current, 


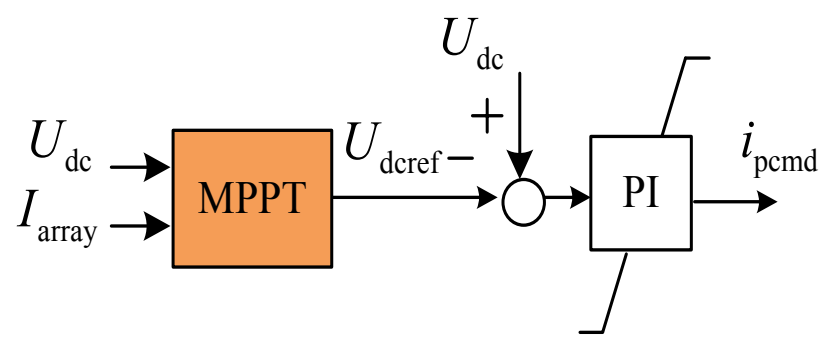

Fig. (5). Schematic of active power control strategy.

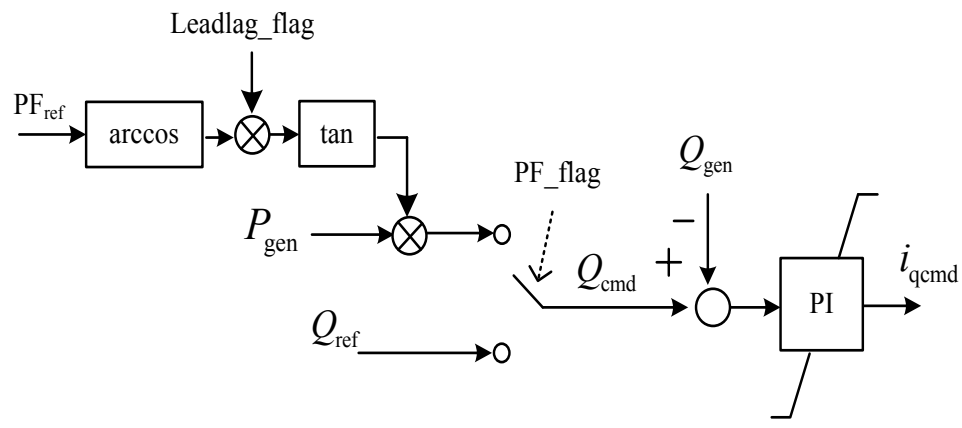

Fig. (6). Schematic of reactive power control strategy.

many inverters are operating with the rated power, so iqcmd can be set to 0 (Fig. 6).

\subsection{Current Amplitude Limiting Strategy}

The strategy limits the current amplitude of inverter in the range of the maximum permissible current imax. And according to the different priorities, the strategies are classified into active power priority mode, reactive power priority mode and equal priority mode.

In active power priority mode:

$$
\left\{\begin{array}{l}
i_{\mathrm{p} \text { max }}=i_{\text {max }} \\
i_{\mathrm{p} \text { min }}=0 \\
i_{\mathrm{q} \text { max }}=\sqrt{i_{\text {max }}^{2}-i_{\mathrm{dref}}^{2}} \\
i_{\mathrm{q} \text { min }}=-\sqrt{i_{\text {max }}^{2}-i_{\mathrm{dref}}^{2}}
\end{array}\right.
$$

In reactive power priority mode:

$$
\left\{\begin{array}{l}
i_{\mathrm{p} \text { max }}=\sqrt{i_{\text {max }}^{2}-i_{\text {qref }}^{2}} \\
i_{\mathrm{p} \text { min }}=0 \\
i_{\text {q } \max }=i_{\text {max }} \\
i_{\text {q } \min }=-i_{\text {max }}
\end{array}\right.
$$

In equal priority mode:

$$
\left\{\begin{array}{l}
i_{\mathrm{p} \text { max }}=I_{\mathrm{max}} i_{\mathrm{pcmd}} / \sqrt{i_{\mathrm{pcmd}}^{2}+i_{\mathrm{qcmd}}^{2}} \\
i_{\mathrm{p} \min }=0 \\
i_{\mathrm{q} \max }=I_{\text {max }} i_{\mathrm{qcmd}} / \sqrt{i_{\mathrm{pcmd}}^{2}+i_{\mathrm{qcmd}}^{2}} \\
i_{\mathrm{q} \min }=-I_{\text {max }} i_{\mathrm{qcmd}} / \sqrt{i_{\mathrm{pcmd}}^{2}+i_{\mathrm{qcmd}}^{2}}
\end{array}\right.
$$

\subsection{Current Control Model}

Generally, the current controller adopts the feed-forward decoupling strategy, including PI control and feed-forward decoupling links, which is shown as Fig. (7).

\subsection{Fault Ride- Through Model}

In order to support the recovery after a power system fault, the grid-connected inverters should have the fault ridethrough function. This function generally includes low voltage ride through and high voltage ride through. Low voltage ride through means that when the voltage at the interconnection point drops, caused by fault or disturbance in the power system, the PV station should ensure the continuous operation and should not disconnect from the grid, in a certain voltage levels and time ranges.

\section{CASE STUDY}

According to the above analysis, a case study is established in the MATLAB with a $500 \mathrm{~kW}$ inverter. The models include three parts: main circuit, PV array and a controller. The rated power of inverter is $500 \mathrm{~kW}$, the rated AC voltage of inverter is $270 \mathrm{~V}$ and the transformer ratio is $270 \mathrm{~V} /$ $36.75 \mathrm{kV}$, as shown in Fig. (7). And the case of grid-side short circuit fault is simulated and analyzed.

In order to support the recovery after a short circuit fault, the inverter should have the low voltage ride through function. It is assumed that switch S1 is closed at the point of $2 \mathrm{~s}$, simulating the three -phase short circuit fault (Fig. 8). The voltage will drop from 1.05 p.u to 0.53 p.u. And then the fault will be cleared at the point $0.5 \mathrm{~s}$, the voltage begins to recover, as shown in Fig. (9). During the simulation, the irradiance and temperature remain unchanged. The inverter was operating in the voltage control mode before the fault occurred. When the controller checks out the fault, the con- 


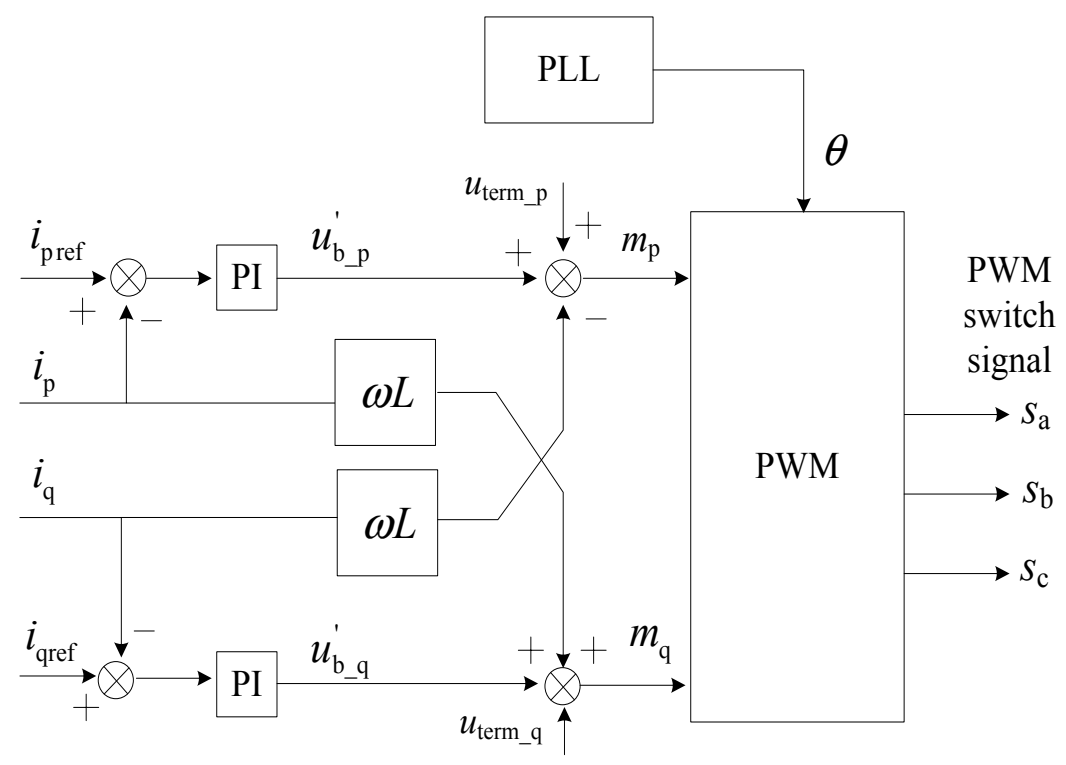

Fig. (7). Schematic of current control strategy.

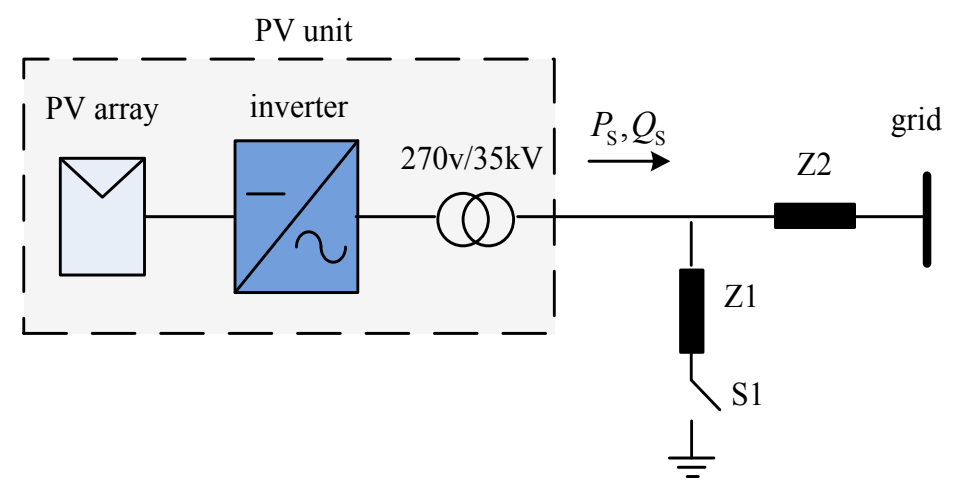

Fig. (8). Schematic of simulation case.

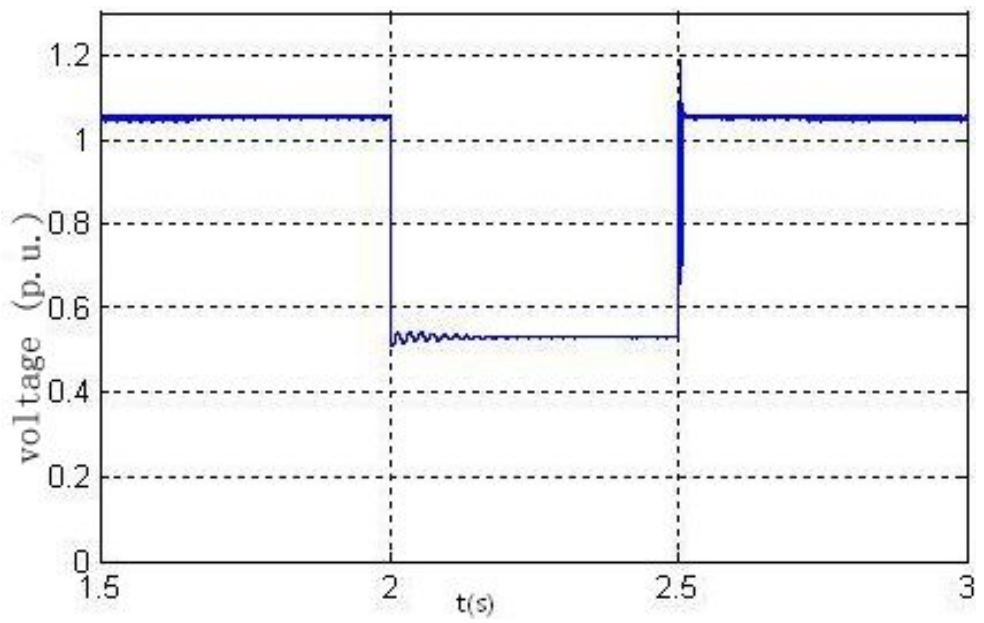

Fig. (9). Response characteristic of voltage.

trol strategy would be converted to fault mode. When the fault was cleared, the system would return to the normal status gradually. The active and reactive power simulation curves are shown as Fig. (10) and Fig. (11). When the fault has been cleared, the PLL and controller need a little time to judge and identify the curve and there is an instantaneous spike, which soon disappears. Due to the adoption of current control mode, the inverter has a very fast response characteristics.

\section{CURRENT \& FUTURE DEVELOPMENTS}

From the above modeling and simulation, it is shown that the PV system is different from the traditional genera- 


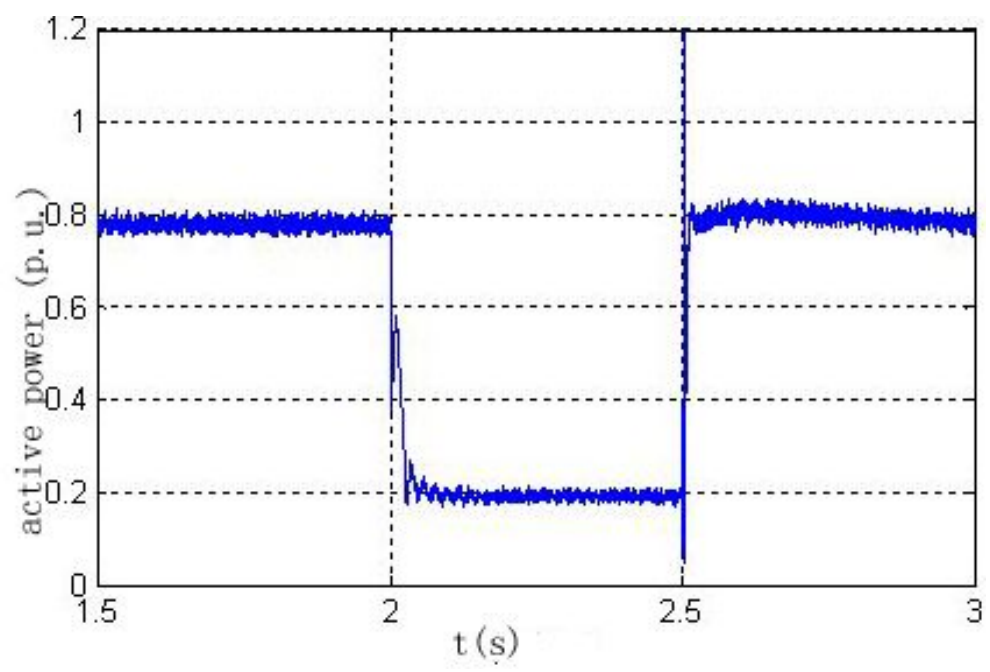

Fig. (10). Response characteristic of active power.

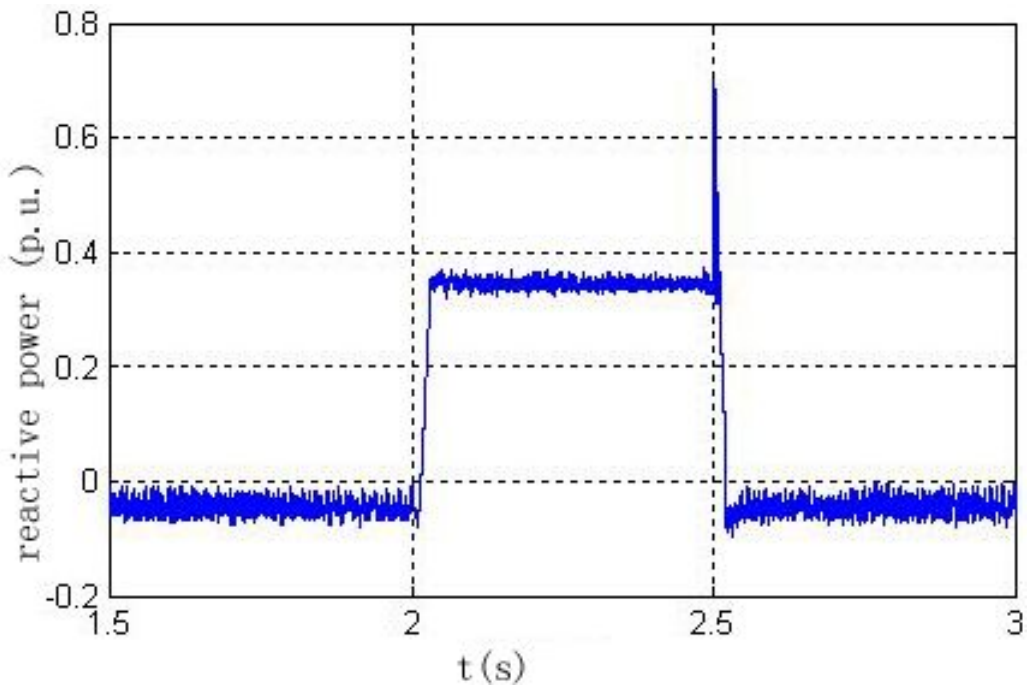

Fig. (11). Response characteristic of reactive power.

tion techniques, and it has very fast response characteristics with little inertia. So these measurements should be necessary for the PV system, especially when a fault occurs or when irradiance changes suddenly. The fault ride through function should a requirement when the PV inverter connects with the grid and will provide support to the power system when recovering. Furthermore, the electromagnetic and electromechanical transient characteristics should be focused on, which needs the further research. The electromechanical models may be modeled through the simplification of electromagnetic models. And the parameters of these models will be identified by the spot test or a laboratory test.

\section{CONFLICT OF INTEREST}

The authors confirm that this article content has no conflict of interest.

\section{ACKNOWLEDGEMENTS}

Declared none.

\section{REFERENCES}

[1] B. Hu, Y. Nonaka, and R. Yokoyama, "Influence of large-scale grid-connected photovoltaic system on distribution networks", $A u$ tomation of Electric Power Systems, vol. 36, no. 3, pp. 34-38, Feb. 2012.

[2] Y. Q. Hou, and W. Li, "Influence of integration of large-scale photovoltaic on grid and key factors restricting its accepted capacity", Power System and Clean Energy, vol. 29, no. 4, pp. 73-77, Apr. 2013.

[3] H. Han, Z. Li, T. Shi, and N. Chen, "Effects of large-scale PV power access on the HVDC power transmission system", Power System and Clean Energy, vol. 29, no. 5, pp. 61-64, May. 2013.

[4] B. Giesler, " $P V$ sub-generator junction box, $P V$ generator junction box, and PV inverter for a PV system, and PV system", U. S. Patent 20110031814 , February 10, 2011.

[5] C. Okatsuchi, " $P V$ module frame, $P V$ module and installation system thereof”, U. S. Patent 20100275974, April 11, 2010.

[6] T. A. Davis, "Photovoltaic-Thermal (PV-T) system for desalination", U. S. Patent 20120085094, Apri 12, 2012.

[7] H. Sun, M. Zhang, Z. Chen, and X. Xie, Q. Jiang, "Comparative study on electromechanical and electromagnetic transient model for grid-connected photovoltaic power system", Power System Protection and Control, vol. 42, no. 3, pp. 128-132, Feb. 2014 .

[8] Y. Wang, X. Zhang, and J. Lu, "Modeling and simulation of gridconnected PV system based on DIgSILENT software", Power Sys- 
tem and Clean Energy, vol. 42, no. 3, pp. 49-54, May. 2014 .

[9] N. Xie, A. Luo, and Y. Chen, "Dynamic modeling and characteristic analysis on harmonics of photovoltaic power stations", Proceedings of the CSEE, vol. 33, no. 36, pp. 10-18, Dec. 2013.

[10] G. Mascolo, "Supported PV module assembly", U. S. Patent 20070144575, June 28, 2007.

[11] C. J. S. Lenox, " $P V$ module frame, $P V$ module and installation system thereof", U. S. Patent 20080000173, April 1, 2008.

[12] H. Urban, A. Thomas, "Installation system for PV modules ", U. S. Patent 20110174353, March 21, 2011.

[13] D. Zhou, Z. Zhao, and L. Wu, "Analysis characteristics of photovoltaic arrays using simulation", $J$ Tsinghua Uninv(Sci\&Tech), vol. 47, no. 7, pp. 1109-1112, Feb. 2007.

[14] X. Kong, Y. Xu, and Y. Zeng, "A parameter extraction method for five-parameter model of photovoltaic cells", Power System Protec- tion and Control, vol. 41, no. 22, pp. 46-51, Nov. 2013.

[15] W. Fu, L. Zhou, and K. Guo, "Research on engineering analytical model of solar cells", Transactions of China Electromechanical Society, vol. 26, no. 10, pp. 211-216, Oct. 2011.

[16] W. Zheng, and X. Xiong, "A Model Identification Method for Photovoltaic Grid-connected Inverters Based on the Wiener Model", Proceedings of the CSEE, vol. 33, no. 36, pp. 18-27, Dec. 2013.

[17] J. Zheng, "Simulation of three-phase photovoltaic grid-connected system based on Matlab/Simulink", Power System and Clean Energy, vol. 29, no. 10, pp. 59-67, Oct. 2013.

[18] Y. Zhang, and J. Zhao, "Modeling and simulation of photovoltaic grid-connected power system", High Voltage Engineering, vol. 36, no. 12, pp. 3097-3098, Dec. 2013.

Received: October 29, 2014

Revised: November 02, 2014

Accepted: November 11, 2014

(C) Shi et al.; Licensee Bentham Open.

This is an open access article licensed under the terms of the Creative Commons Attribution Non-Commercial License (http://creativecommons.org/licenses/by-nc/3.0/) which permits unrestricted, non-commercial use, distribution and reproduction in any medium, provided the work is properly cited. 